\title{
Thrombospondins Differentially Regulate Proteins Involved in Arterial Remodeling
}

\author{
M. M. KASSEM ${ }^{1,2}$, A. HELKIN ${ }^{1,2}$, K. G. MAIER ${ }^{1,2} *$, V. GAHTAN ${ }^{1,2} *$ \\ *These authors contributed equally to this work. \\ ${ }^{1}$ SUNY Upstate Medical University, Division of Vascular Surgery and Endovascular Services, \\ Syracuse, New York, USA, ${ }^{2}$ Department of Veterans Affairs VA Healthcare Network Upstate New \\ York at Syracuse, Syracuse, New York, USA
}

Received February 20, 2019

Accepted July 7, 2019

Epub Ahead of Print October 25, 2019

\begin{abstract}
Summary
Thrombospondins (TSPs) are matricellular glycoproteins expressed in response to vascular injury. TSP-1 and TSP-2 are promotors of arterial remodeling while TSP- 5 is believed to be protective. The current study assessed the differential effect of TSPs on protein expression in vascular smooth muscle cells (VSMCS). We hypothesized that TSP-1, TSP-2 and TSP-5 would regulate VSMC proteins involved in arterial remodeling. Human VSMCs were exposed to TSP-1, $-2,-5$ or serum free media (24 hours). Cell lysates were used to assess the targets TSP-1, TSP-2, TSP-5 and CD44), while the culture media was used to detect TGF- $\beta 1$, PDGF-BB, ANGPTL-4 and IL-8. Statistical analysis was performed by $t$-test and $p<0.05$ was considered significant. All TSPs increased their own expression and TSP-5 increased TSP-2. TSP-1 and TSP-2 increased production of ANGPTL-4 and PDGF-BB, while TSP-5 only increased ANGPTL-4. TSP-1 increased exclusively TGF- $\beta 1$ and CD44 production. TSP-2 increased TSP-1 expression. All TSPs decreased IL-8. The findings suggest that TSP-1 and TSP-2 may promote vascular remodeling, in part, by increasing ANGPTL-4, PDGF-BB and their own expression. TSP-5 did not upregulate the inflammatory mediators TSP-1, PDGF-BB or TGF- $\beta 1$, but upregulated its own expression, which could be a protective mechanism against the response to vascular injury.
\end{abstract}

\section{Key words}

Gene expression - Protein expression - Thrombospondins • Vascular smooth muscle cells $\bullet$ Vascular remodeling

\section{Corresponding author}

V. Gahtan, Loyola University Chicago, Health Sciences Division,
2160 SouthFirst Ave., Maywood, IL 60153, USA. Email: Vivian.Gahtan001@lumc.edu

\section{Introduction}

The TSPs are a group of multifunctional matricellular glycoproteins, which are regulators of intimal hyperplasia. TSPs are divided based on their chemical structure into 2 groups: Group A (TSP-1, TSP-2) and Group B (TSP-3, TSP-4 and TSP-5) (Dickinson et al. 2003, McKenzie et al. 2006). The focus of this study is on TSP-1, TSP-2 and TSP-5, as they are all associated with arterial disease.

TSP-1 is the most studied of the TSPs for its role in arterial disease. TSP-1 levels are increased in the presence of $\mathrm{PAD}$, abundant in complex atherosclerotic plaque, and blocking TSP-1 decreases intimal hyperplasia (Adams, 1997). TSP-1 has been heavily investigated as an antiangiogenic glycoprotein, but in addition is stored in platelet $\alpha$-granules and released upon platelet activation, and induces vascular smooth muscle cell (VSMC) proliferation and migration. TSP-2 has been less well studied but does share some functions with TSP-1, such as inhibiting angiogenesis, inducing endothelial cell apoptosis, VSMC proliferation and migration (Helkin et al. 2015). Although the functional relationship of TSP-2 to intimal hyperplasia is less established, TSP-2 induces VSMC attachment to the extracellular matrix, and is upregulated in neointimal tissues (Bodewes et al. 2017). The similarity in functions are probably due to the 
similarity of chemical structure between TSP-1 and TSP-2 (Helkin et al. 2015).

TSP-5, also known as cartilage oligomeric matrix protein (COMP), has some distinctly different functions from TSP-1 and TSP-2, and is potentially protective against the development of intimal hyperplasia (Du et al. 2011, Liang et al. 2015, Wang et al. 2010). TSP-5 is involved in maintaining vascular homeostasis, as TSP-5 is secreted via platelets and specifically inhibits thrombin-induced platelet aggregation and activation (Liang et al. 2015). Recent studies show that TSP-5 plays a crucial role in preventing vascular intimal hyperplasia, calcification and remodeling (Du et al. 2011, Wang et al. 2010). TSP-5 does not induce VSMC proliferation, which is likely due the lack of the proliferative CD36 receptor binding domain that TSP-1 and TSP-2 have (Helkin et al. 2015). In contrast, TSP-1, TSP-2 and TSP-5 all induce VSMC migration (Helkin et al. 2015). The mechanism is likely due to all three containing the CD47 binding domain, which is associated with cell migration (Helkin et al. 2015).

Platelet activation occurs immediately after endothelial injury of a peripheral artery (Cassar et al. 2003). Activated platelets release multitude of substances including platelet derived growth factor-BB (PDGF-BB), interleukin-8 (IL-8), transforming growth factor- $\beta 1$ (TGF- $\beta 1$ ), and TSP-1 (Cassar et al. 2003) The subsequent VSMC migration, proliferation and extracellular matrix development in turn leads to vascular remodeling and intimal hyperplasia (Cassar et al. 2003).

TSPs exert many of their effects on VSMCs by affecting gene expression. Previously we showed that TSP-1, TSP-2 and TSP-5 each alter gene expression of genes associated with arterial remodeling (THBS1, THBS2, CD44, PDGFB, ANGPTL4, CXCL8 and TGFB1) (Helkin et al. 2015). The current study assessed the expression of these genes at the protein level by TSP-1, -2 and -5. We hypothesized that TSP-1, TSP-2 and TSP-5 would regulate VSMC protein expression involved in arterial remodeling.

\section{Methods}

\section{Materials}

TSP-1 was purchased from Athens Research (Athens, GA). Recombinant TSP-2 and TSP-5 were obtained from R\&D Systems (Minneapolis, MN). Smooth muscle cell growth medium was purchased from Cell Applications, Inc. (San Diego, CA). $0.2 \%$ Fetal
Bovine Serum added to smooth muscle basal media was used as serum-free media (SFM).

\section{Cell Culture}

Human aortic VSMCs were obtained from Cell Applications, Inc. (San Diego, CA, USA) and used in early passage (P5). Cells were made quiescent by incubation in SFM for 48 hours at $37^{\circ} \mathrm{C}$ in a tissue culture incubator $\left(5 \% \mathrm{CO}_{2}\right)$.

\section{Cell Treatment}

Confluent VSMCs $(>90 \%)$ were treated with TSP-1, TSP-2 or TSP-5 at the previously established concentration of $20 \mu \mathrm{g} / \mathrm{ml}$ or SFM, as a negative control, for 24 hours (Helkin et al. 2015). Cells were harvested, centrifuged at $14,000 \mathrm{rpm}$ for 10 minutes. Cell Culture supernate (media) was collected and stored in $-80{ }^{\circ} \mathrm{C}$. Cell pellets were rinsed and lysed using protease inhibitor cocktail purchased from SIGMA-ALDRICH (St. Louis, MO) and diluted in RIPA buffer obtained from Thermo scientific (Rockford, IL). Cell lysate protein extracts were used to assess the targets TSP-1, TSP-2, TSP-5 and CD44. While the cell culture supernate media was used to assess the targets IL-8, PDGF-BB, TGF- $\beta 1$ and ANGPTL-4.

\section{$R N A$ isolation and $c D N A$ reverse transcription}

The effect of TSP-1, TSP-2 or TSP-5 on COMP (target gene for TSP-5) expression in VSMCs of had not been done previously and therefore was added to the current study. Quiescent cells were exposed to SFM, TSP-1, TSP-2 or TSP-5 (20 $\mu \mathrm{g} / \mathrm{ml})$ for 3 , 6 or 24 hours. Media was decanted and cells frozen to $-80^{\circ} \mathrm{C}$. RNA was extracted using RNeasy kit (Qiagen, Germantown, MD). Quality of the RNA samples was assessed using an Agilent Bioanalyzer (Agilent Technologies, Santa Clara, CA). cDNA was generated using the high capacity cDNA Reverse transcription kit (Applied Biosystems, Grand Island, NY) using a C1000 Touch Thermocycler (BioRad, Hercules, CA).

Real-time quantitative reverse transcriptase-polymerase chain reaction

TaqMan ${ }^{\circledR}$ Gene primers for $C O M P$ and $G A P D H$ (House Keeping gene) run on a QuantStudio 7 Flex Realtime PCR system (Applied Biosystems, Grand Island, $\mathrm{NY}$ ) were used to determine gene expression in the SFM, TSP-1, TSP-2 and TSP-5 samples at 3, 6 and 24 hours. 


\section{Total Protein Assay}

Total protein concentration in the examined samples was quantified using DC Protein Assay purchased from Bio-Rad Laboratories Inc. (Hercules, $\mathrm{CA})$ according to the manufacturer instructions.

\section{Western Blotting}

TSP-2, TSP -5 and ANGPTL-4 expression were determined using western blot. Cell lysate proteins (in TSP-2 and TSP-5 experiments) and cell culture media (ANGPTL-4 experiment) were subjected to gel electrophoresis at $200 \mathrm{mV}$ for $50 \mathrm{~min}$ (Criterion TGX stain free gel purchased from Bio-Rad Laboratories Inc., Hercules, CA; $12 \%$ SDS for TSP-2 and TSP-5, $18 \%$ SDS for ANGPTL-4). Then, the proteins were transferred to a polyvinylidene (PVDF) membrane using trans-blot turbos (Bio-Rad Laboratories Inc.). The blot was blocked using $5 \%$ skim milk in TBST for one hour and then incubated with the appropriate primary antibody (1:1000 concentration) diluted in $2 \%$ TBST containing skim milk -(polyclonal goat TSP-2 and TSP-5 antibodies purchased from R\&D Systems, Minneapolis, MN; mouse monoclonal ANGPTL-4 antibody purchased from Santa Cruz Biotechnology Inc. Santa Cruz, CA)- overnight at $4{ }^{\circ} \mathrm{C}$. The next day blots were washed with TBST solution three times for ten minutes each then incubated with the appropriate secondary antibody (Goat IgG Horseradish peroxidase-conjugated purchased from R\&D Systems in TSP-2, TSP-5 experiments, Mouse IgG peroxidase-conjugate antibody purchased from Santa Cruz Biotechnology in ANGPTL-4 experiment) diluted in TBST containing $2 \%$ skim milk (1:2000 concentration) for one hour at room temperature. Blot membranes were washed with TBST three times for ten minutes each. Clarity Western ECL Chemiluminescent substrate was used to detect bound antibodies. Protein bands were analyzed via Bio-Rad Image Lab Software. The target proteins were normalized with total proteins loaded on the SDS-PAGE gel and represented by the ratio of target protein signal to the total proteins control signal.

\section{ELISA}

TSP-1 expression in cell lysate protein was measured using ELISA Quantikine ${ }^{\circledR}$ Human Thrombspondin-1 Immunoassay Kit (R\&D Systems USA, Minneapolis, MN). PDGF-BB levels were detected in the cell culture supernate using ELISA Quantikine ${ }^{\circledR}$ Human PDGF-BB Immunoassay Kit (R\&D Systems USA, Minneapolis, MN). TGF- $\beta 1$ in the cell culture media was measured using ELISA Quantikine ${ }^{\circledR}$ Human TGF- $\beta 1$ Immunoassay Kit (R\&D Systems USA, Minneapolis, MN). IL-8 concentrations were quantified using the ELISA Quantikine ${ }^{\circledR}$ Human CXCL-8/IL-8 Immunoassay Kit (R\&D Systems USA, Minneapolis, $\mathrm{MN})$. CD44 expression in cell lysate proteins was quantified using Novus Biologicals Human CD44 ELISA Kit (Littleton, CO, USA). Samples were diluted according to the manufacturer's instructions. The concentration read off the standard curve multiplied by the dilution factor.

\section{Statistical analysis}

Quantitative data are presented as the mean \pm standard error. Student's $t$-test was used to determine the significance for all pairwise comparisons of interest. $p<0.05$ was considered to indicate a statistically significant difference.

\section{Results}

\section{COMP gene expression}

TSP-1, TSP-2 and TSP-5 each upregulated the expression of COMP at three hours (fold change 0.15, $0.16,0.38$ respectively; $\mathrm{p}<0.05$ ); while TSP-1 and TSP-2 downregulated COMP expression at six hours (fold change $0.23,0.19$ respectively; $p<0.05$ ). No significant change was observed at 24-hour time point, although there was a trend of increased COMP expression in all treatment groups (RQ values 1.43, 1.27, 1.84 respectively).

TSP-1 expression was upregulated by TSP-1 and TSP-2, but not TSP-5

Basal TSP-1 expression was not detectable in SFM treated VSMCs. TSP-1 expression went from undetectable to detectable in TSP-1 and TSP-2 treated VSMCs. As the control was zero there is no way to quantify a fold change. By ELISA, we found TSP-1 increased its own expression to $12.4 \mathrm{ng} / \mu \mathrm{g}$ protein while TSP-2 upregulated TSP-1 to $0.25 \mathrm{ng} / \mu \mathrm{g}$ protein (Fig. 1A). In contrast, TSP-5 did not induce TSP-1 expression by VSMCs.

\section{TSP-2 expression was upregulated by TSP-2 and TSP-5}

The TSP-2 signal was identified at $129 \mathrm{KDa}$ by western blot analysis (Fig. 1B). Densitometry is summarized in Fig. 1C. Increased band intensity was appreciated by TSP-2 (p=0.005) and TSP-5 groups 
$(\mathrm{p}=0.03)\left(14.1 \times 10^{7}\right.$ adjusted band density, $6.4 \times 10^{7}$ adjusted band density, respectively).

\section{TSP-5 upregulated its own expression}

The TSP-5 signal was identified at $120 \mathrm{KDa}$ using western blot analysis (Fig. 1C). TSP-5 was only detected in TSP- 5 treated cells $(27.8 \times 107$ adjusted band density). TSP-5 expression was not detectable in any of the other treatment groups (Fig. 1C).

PDGF-BB production was increased by TSP-1 and TSP-2

Basal PDGF-BB production was detected in VSMC media. By ELISA, we found that TSP-1 $(\mathrm{p}=0.02)$ and TSP-2 $(\mathrm{p}=0.02)$ increased PDGF production to 0.85 , $0.65 \mathrm{pg} / \mu \mathrm{g}$ protein (Fig. 2A). PDGF-BB production was detected in the TSP-5 group $(0.25 \mathrm{pg} / \mu \mathrm{g})$ similar to that of the SFM group $(0.24 \mathrm{pg} / \mu \mathrm{g})$.

\section{TGF-B1 production was increased solely by TSP-1}

TSP-1 increased TGF- $\beta 1$ production $(\mathrm{p}=0.01)$ into the media to $65 \mathrm{pg} / \mu \mathrm{g}$. TGF- $\beta 1$ production in the TSP-2 and TSP-5 groups trended lower $(30.7,30.3 \mathrm{pg} / \mu \mathrm{g}$ protein), but the difference did not reach statistical significance when compared to SFM cells (48.2 pg/ $\mu \mathrm{g}$; Fig. 2B).

\section{IL-8 production was decreased by all TSPS}

TSP-1, TSP-2 and TSP-5 each decreased the production of IL- 8 in the VSMC media compared to the negative control. By ELISA, we found that basal IL-8 production by SFM treated cells was $104 \mathrm{pg} / \mu \mathrm{g}$ protein. TSP-1 $(p=0.003)$, TSP-2 $(p=0.0024)$ and TSP-5 $(p=0.04)$ each decreased IL- 8 production to $17.5,27,32.1 \mathrm{pg} / \mu \mathrm{g}$ respectively (Fig. 2C).

\section{ANGPTL-4 production was increased by all TSPS}

ANGPTL-4 signal was identified using western blot analysis (Fig. 2D). TSP-1 $(p=0.04)$ was found to increase ANGPTL-4 production by 6.2-fold. TSP-2 $(p=0.02)$ and TSP-5 $(p=0.02)$ increased ANGPTL-4 production by 25 -fold when compared to the negative control (Fig. 2E).

\section{CD44 expression was increased by TSP-1}

Basal expression of CD44 in SFM cells was $0.6 \mathrm{ng} / \mu \mathrm{g}$ protein. TSP-1 increased CD44 expression by VSMCs. By ELISA, TSP-1 ( $\mathrm{p}=0.03)$ increased CD44 levels to $0.8 \mathrm{ng} / \mu \mathrm{g}$ protein (Fig. $2 \mathrm{E}$ ).
1.A

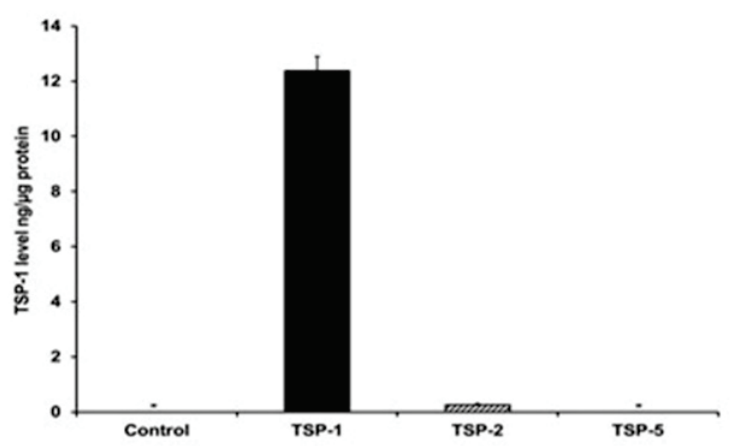

1.B $129 \mathrm{kDa}$

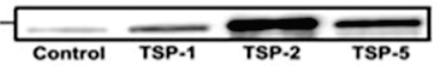
TSP-2

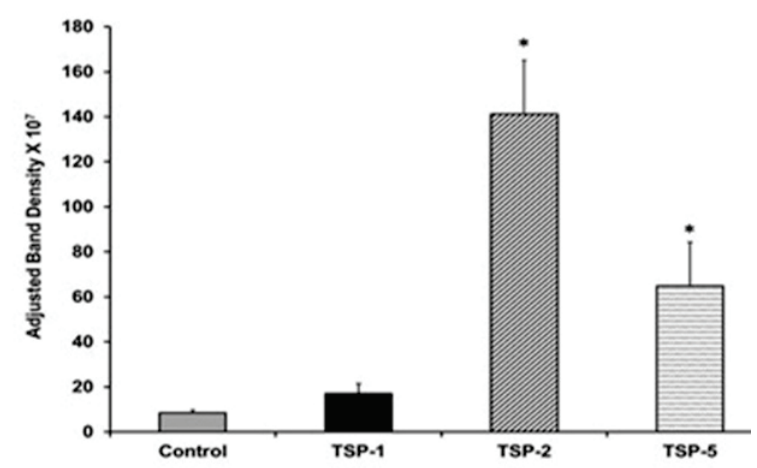

1.C
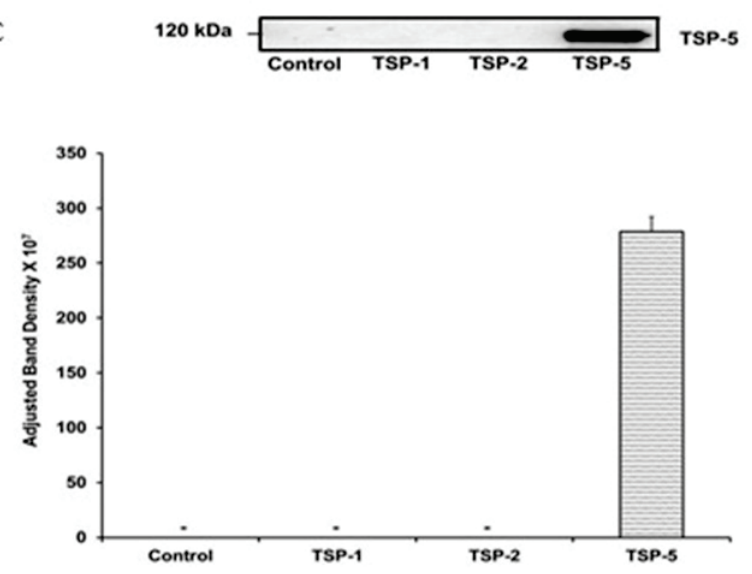

Fig. 1. Effect of the TSPs on each other. (A) TSP-1 protein expression by TSP-1, TSP-2 and TSP- 5 treated VSMCs. TSP-1 levels, measured by ELISA, showed TSP-1 went from undetectable to detectable in TSP- 1 and -2 treated cells. TSP-1 signal was not detectable in either the control or the TSP-5 treated cells. (B) Western blot demonstrates TSP-2 upregulation by VSMCs stimulated by TSP-2. The quantitative adjusted band density demonstrates upregulation of TSP-2 expression by TSP-2 or TSP-5. Total protein was used as an internal loading control. ${ }^{*} \mathrm{p}<0.05, \mathrm{n}=3$. (C) Western blot demonstrates TSP-5 expression is only detectable in TSP-5 treated cells. TSP-5 signal was not identified in any other treatment group. Quantitative adjusted band density of TSP-5 expression. 


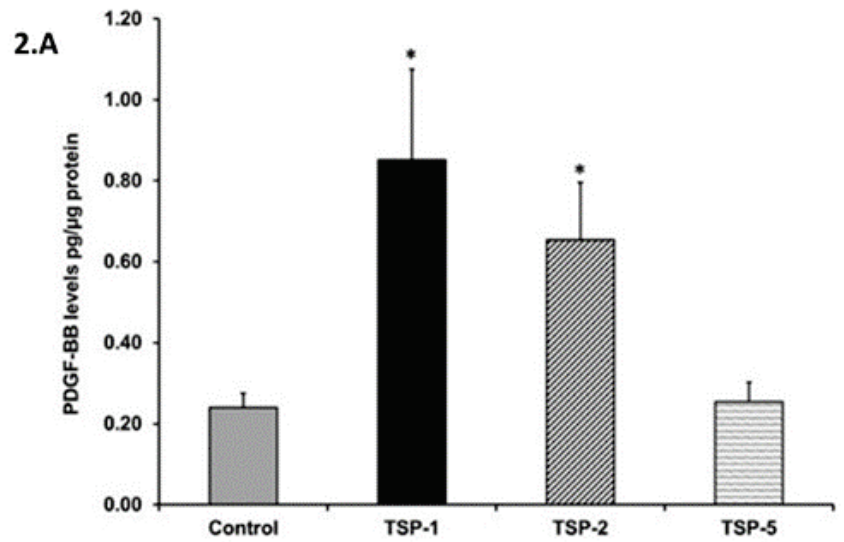

2.D
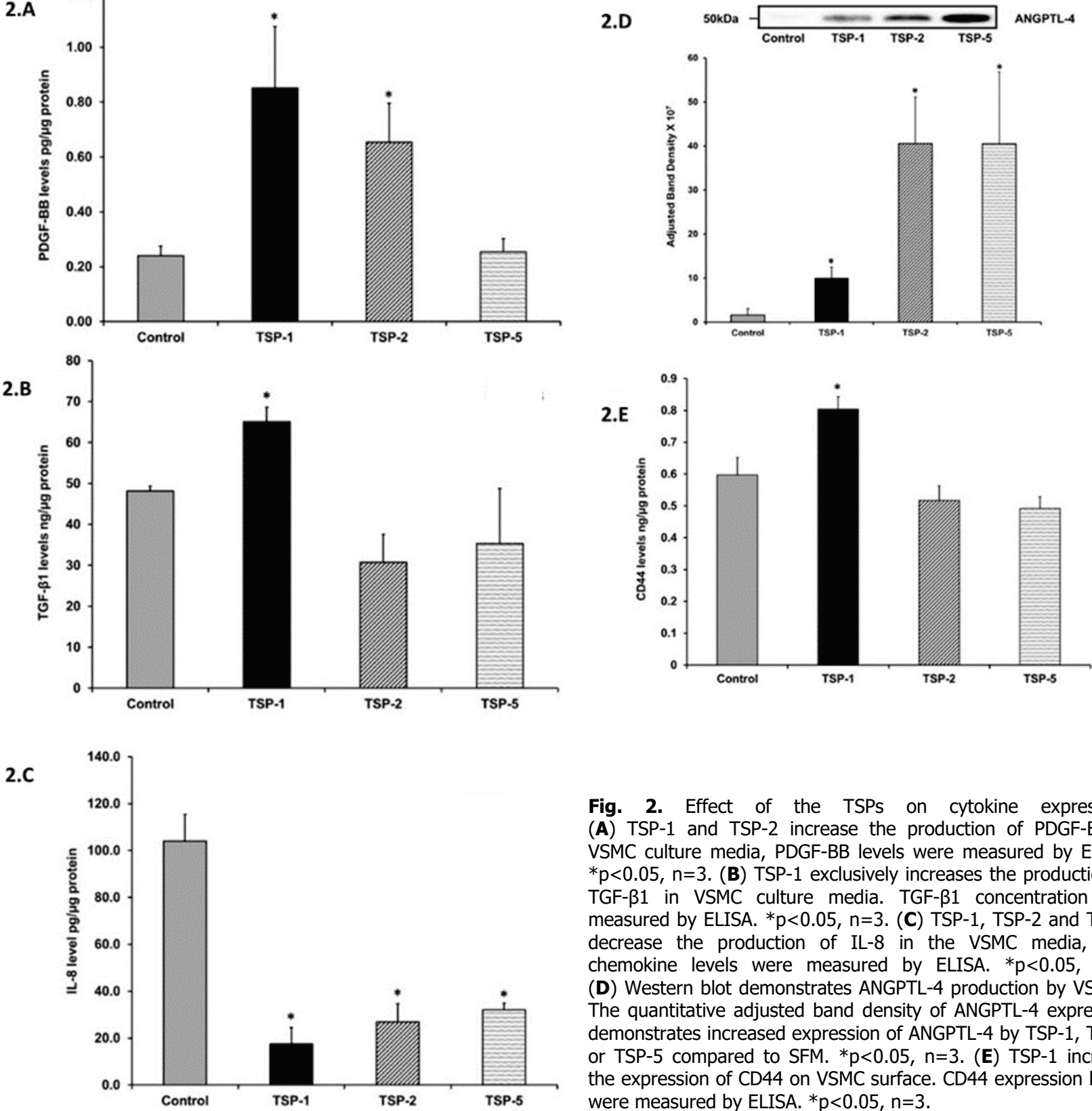

Fig. 2. Effect of the TSPs on cytokine expression. (A) TSP-1 and TSP-2 increase the production of PDGF-BB in VSMC culture media, PDGF-BB levels were measured by ELISA. $* \mathrm{p}<0.05, \mathrm{n}=3$. (B) TSP-1 exclusively increases the production of TGF- $\beta 1$ in VSMC culture media. TGF- $\beta 1$ concentration was measured by ELISA. ${ }^{*} p<0.05, n=3$. (C) TSP- 1, TSP- 2 and TSP- 5 decrease the production of IL-8 in the VSMC media, IL-8 chemokine levels were measured by ELISA. ${ }^{*} p<0.05, n=3$. (D) Western blot demonstrates ANGPTL-4 production by VSMCs. The quantitative adjusted band density of ANGPTL-4 expression demonstrates increased expression of ANGPTL-4 by TSP-1, TSP-2 or TSP-5 compared to SFM. ${ }^{*} p<0.05, n=3$. (E) TSP-1 increase the expression of CD44 on VSMC surface. CD44 expression levels were measured by ELISA. ${ }^{*} \mathrm{p}<0.05, \mathrm{n}=3$.

\section{Discussion}

TSPs are acute phase reactants that are expressed at the site of vascular injury where they are intimately involved in vascular remodeling (McKenzie et al. 2006). Previously we have shown that TSP-1, TSP-2 and TSP-5 regulate the expression of genes involved in intimal hyperplasia (Helkin et al. 2015). How the TSPs affect remodeling, at least in part, is by the regulation of proteins associated with intimal hyperplasia. Our findings and their implications are summarized below.

TSP-1, an endogenous protein which is secreted by platelets in response to arterial injury, is the TSP most associated with intimal hyperplasia and arterial

remodeling (Adams, 1997). TSP-2 and TSP-5 are molecules that have recently been linked to vascular remodeling and intimal hyperplasia as well; however, little is known regarding the exact role of TSP-2 and TSP-5 in the pathogenesis of intimal hyperplasia (Bodewes et al. 2017, Liang et al. 2015, Wang et al. 2010). The similarity in the chemical structure of TSP-2 to TSP-1 may explain why TSP-1 and TSP-2 may have similar intimal hyperplastic properties (Helkin et al. 2015). In one study, TSP-2 was shown to have a potential role in promoting intimal hyperplasia after arterial injury (Bodewes et al. 2017). In contrast, TSP-5 may be protective against intimal hyperplasia and vascular remodeling. (Du et al. 2011) In the current study, TSP-1 
expression was significantly higher in TSP-1 treated cells when compared to TSP-2 treatment; however, the fact that TSP-2 induced TSP-1 expression is a novel finding and may explain, at least in part, the intimal hyperplastic properties of TSP-2. In contrast, TSP-5 did not increase TSP-1 which may support our hypothesis that TSP-5 is protective against intimal hyperplasia. We further investigated TSP-2 expression in VSMCs in response to the three TSPs and found that TSP-2 expression was upregulated by TSP-2 and TSP-5 treatment. The implication(s) of TSP-2 increasing TSP-5 expression in VSMCs warrants further investigation. Finally, TSP-5 treated VSMCs showed an increase in TSP-5 expression. Therefore, each TSP increased its own expression in an apparent feed forward signaling mechanism.

Platelet derived growth factors (PDGFs) are potent VSMC agonists that have been heavily investigated (Raines, 2004). PDGFs are involved in vascular remodeling as they stimulate VSMC proliferation and migration (Pan et al. 2017). Our previous study found that PDGFB gene expression went from undetectable to detectable at 6 hours in VSMCs after TSP-1, TSP-2 or TSP-5 treatment (Helkin et al. 2015). Consistent with this finding, the current study showed increased PDGF-BB production in VSMCs stimulated by TSP-1 and TSP-2. These results support the hypothesis that TSP-1 and TSP-2 each induce remodeling in part by increasing the production of PDGF-BB. In contrast, TSP-5 had no effect on PDGF-BB production. TGF- $\beta 1$ is a cytokine that plays an important role in cellular proliferation, migration, angiogenesis and vascular remodeling (Wendan et al. 2016). We found that TSP-1, but not TSP-2 or TSP-5 increased TGF- $\beta 1$ production. TSP-1 and TGF- $\beta 1$ are integrally linked (Schultz-Cherry et al. 1993). That TGF- $\beta 1$ increases TSP-1 production may be another example of a feedforward loop which serves to increase the progression of vascular disease.

IL-8 is a cytokine secreted by macrophages, neutrophils, endothelial cells and VSMCs, and is a potent inducer of VSMC migration and proliferation (Apostolakis et al. 2009). Previously we found that TSPs downregulated the CXCL8 gene which encodes IL-8 (Helkin et al. 2015). In the current study, TSP-1, TSP-2 and TSP-5 decreased IL-8 production. IL-8 downregulation by TSP-1 could be explained by the fact that TSP-1 increases the transcription of miR-520c and miR-519d, which are microRNAs that target IL-8. However, the finding that TSP-2 and TSP-5 decrease IL-8 is interesting and needs further investigation (Maier et al. 2016, Vlachos et al. 2015). While IL-8 is known to be increased in areas of vascular injury, the source cells are likely to be cells other than VSMCs (Apostolakis et al. 2009).

Table 1. Comparison of protein expression to previously identified up and downregulated genes at different time points

\begin{tabular}{|c|c|c|c|c|c|c|}
\hline \multirow[t]{3}{*}{ Target } & \multicolumn{6}{|c|}{ Treatment } \\
\hline & \multicolumn{2}{|c|}{ TSP-1 } & \multicolumn{2}{|c|}{ TSP-2 } & \multicolumn{2}{|c|}{ TSP-5 } \\
\hline & Gene & Protein & Gene & Protein & Gene & Protein \\
\hline$T S P-1$ & $\uparrow(6 h)^{*}$ & $\uparrow$ & $\uparrow(6 h)^{*}$ & $\uparrow$ & $\uparrow(24 h)^{*}$ & Undetectable \\
\hline$T S P-2$ & $\leftrightarrow^{*}$ & $\leftrightarrow$ & $\leftrightarrow^{*}$ & $\uparrow$ & $\uparrow\left(3,6,24 \mathrm{~h}^{*}\right)$ & $\uparrow$ \\
\hline$T S P-5$ & $\downarrow(3,6 \mathrm{~h})$ & Undetectable & $\downarrow(3,6 \mathrm{~h})$ & Undetectable & $\downarrow(3 h)$ & $\uparrow$ \\
\hline$P D G F-B B$ & Detectable* & $\uparrow$ & Detectable* & $\uparrow$ & Detectable* & $\leftrightarrow$ \\
\hline$T G F-B 1$ & $\uparrow(24 h)^{*}$ & $\uparrow$ & $\leftrightarrow^{*}$ & $\leftrightarrow$ & $\leftrightarrow^{*}$ & $\leftrightarrow$ \\
\hline$I L-8$ & $\downarrow(6,24 \mathrm{~h})^{*}$ & $\downarrow$ & $\downarrow(24 \mathrm{~h})^{*}$ & $\downarrow$ & $\downarrow(24 h)^{*}$ & $\downarrow$ \\
\hline$A N G P T L-4$ & $\uparrow(24 h)^{*}$ & $\uparrow$ & $\uparrow(24 h)^{*}$ & $\uparrow$ & $\uparrow(6,24 \mathrm{~h})^{*}$ & $\uparrow$ \\
\hline$C D 44$ & $\uparrow(24 h)^{*}$ & $\uparrow$ & $\leftrightarrow^{*}$ & $\leftrightarrow$ & $\uparrow(3 h)^{*}$ & $\leftrightarrow$ \\
\hline
\end{tabular}

*Previously published gene data (Helkin, et al., 2015), $\uparrow=$ Upregulation, $\downarrow=$ Downregulation, $\leftrightarrow=$ No change, ()$=$ Time

ANGPTL-4 is a secreted matricellular protein that shares a structural motif with the angiopoietins (Sukonina et al. 2006, Xu et al. 2015). The effect of TSPs on the ANGPTL4 gene was only described recently when we examined the differential effects of TSPs on VSMC physiology (Helkin et al. 2015). ANGPTL-4 plays a key role in disruption of endothelial integrity and alteration of vascular permeability. Interestingly, we found that TSP-1, 
TSP-2 and TSP-5 increase the production of ANGPTL-4 by $6.2,25$, and 25 fold respectively (Xu et al. 2015). Upregulation of the multifunctional secreted protein ANGPTL-4 potentially indicates that TSPs not only play a crucial role not only affecting VSMCs, but also through an indirect influence on nearby endothelial cells (Xu et al. 2015).

Components of the extracellular matrix are involved in the vascular remodeling process that occurs after arterial injury (Maier et al. 2009). One of these components is hyaluronic acid (HA), which regulates VSMC proliferation and chemotaxis (Toole et al. 2002). HA exerts many of its effects through binding to the CD44 receptor (Toole et al. 2002). In a previous study we showed that blocking CD44 blunted TSP-1 induced VSMC migration (Maier et al. 2009). The current study showed that only TSP-1 increased the expression of CD44 which further supports TSP-1's role in intimal hyperplasia formation.

The current study sought to determine whether the TSPs effect on protein expression mimicked the expression changes seen in the respective genes. The results demonstrate, with little exception, that the protein expression did follow a similar pattern to gene expression indicating highly regulated intracellular signaling (Table 1).

\section{Conclusions}

Substantial differences exist in VSMC protein expression patterns following exposure to the different TSPs. These results agree with our previous gene expression study in VSMCs treated with TSP-1, TSP-2 or TSP-5. Our findings suggest a feed forward mechanism where all TSPs increase their own expression. Furthermore, TSP-2 increases TSP-1 levels. To the best of our knowledge, this is the first study demonstrating the effect of TSPs on their own protein expression and on each other by VSMCs. This study suggests that TSP-1 and TSP-2 promote intimal hyperplasia, in part, by increasing ANGPTL-4, PDGF-BB and their own expression. TSP-5 may be protective against remodeling as it upregulates its own expression, but not TSP-1, PDGF-BB or TGF- $\beta 1$. These findings indicate that TSP-1 and TSP-2 may act in a synchronous manner to promote vascular remodeling, while TSP-5 may impede remodeling.

\section{Conflict of Interest}

There is no conflict of interest.

\section{Acknowledgements}

This study was supported by a NIH Grant \# HL 133577. The funding source had no involvement in any portions of study design, data collection, analysis or decision to submit. This data was presented at the annual meeting of the Academic Surgical Congress, Jacksonville, FL. January 2018.

\section{Author Contribution}

Mohammed Kassem performed all the experiments in this work, wrote the manuscript draft. Alex Helkin helped prepare and edit the manuscript and did the gene work that formed the basis of our current work. Kristopher Maier and Vivian Gahtan are the principle investigators who equally formulated the hypothesis, provided consults about technical aspects of the work and edited the manuscript.

\section{References}

ADAMS JC: Thrombospondin-1. Int J Biochem Cell Biol 29: 861-865, 1997.

APOSTOLAKIS S, VOGIATZI K, AMANATIDOU V, SPANDIDOS DA: Interleukin 8 and cardiovascular disease. Cardiovasc Res 84: 353-360, 2009.

BODEWES TC, JOHNSON JM, AUSTER M, HUYNH C, MURALIDHARAN S, CONTRERAS M, LOGERFO FW, PRADHAN-NABZDYK L: Intraluminal delivery of thrombospondin-2 small interfering RNA inhibits the vascular response to injury in a rat carotid balloon angioplasty model. FASEB J 31: 109-119, 2017.

CASSAR K, BACHOO P, BRITTENDEN J: The role of platelets in peripheral vascular disease. Eur J Vasc Endovasc Surg 25: 6-15, 2003.

DICKINSON SC, VANKEMMELBEKE MN, BUTTLE DJ, ROSENBERG K, HEINEGARD D, HOLLANDER AP: Cleavage of cartilage oligomeric matrix protein (thrombospondin-5) by matrix metalloproteinases and a disintegrin and metalloproteinase with thrombospondin motifs. Matrix Biol 22: 267-278, 2003. 
DU Y, WANG Y, WANG L, LIU B, TIAN Q, LIU CJ, ZHANG T, XU Q, ZHU Y, AKE O, QI Y, TANG C, KONG W, WANG X: Cartilage oligomeric matrix protein inhibits vascular smooth muscle calcification by interacting with bone morphogenetic protein-2. Circ Res 108: 917-928, 2011.

HELKIN A, MAIER KG, GAHTAN V: Thrombospondin-1, -2 and -5 have differential effects on vascular smooth muscle cell physiology. Biochem Biophys Res Commun 464: 1022-1027, 2015.

LIANG Y, FU Y, QI R, WANG M, YANG N, HE L, YU F, ZHANG J, YUN CH, WANG X, LIU J, KONG W: Cartilage oligomeric matrix protein is a natural inhibitor of thrombin. Blood 126: 905-914, 2015.

MAIER KG, RUHLE B, STEIN JJ, GENTILE KL, MIDDLETON FA, GAHTAN V: Thrombospondin-1 differentially regulates microRNAs in vascular smooth muscle cells. Mol Cell Biochem 412: 111-117, 2016.

MAIER KG, SADOWITZ B, CULLEN S, HAN X, GAHTAN V: Thrombospondin-1-induced vascular smooth muscle cell migration is dependent on the hyaluronic acid receptor CD44. Am J Surg 198: 664-669, 2009.

MCKENZIE P, CHADALAVADA SC, BOHRER J, ADAMS JC: Phylogenomic analysis of vertebrate thrombospondins reveals fish-specific paralogues, ancestral gene relationships and a tetrapod innovation. BMC Evol Biol 6: 33, 2006.

PAN S, LIN H, LUO H, GAO F, MENG L, ZHOU C, JIANG C, GUO Y, JI Z, CHI J, GUO H: Folic acid inhibits dedifferentiation of PDGF-BB-induced vascular smooth muscle cells by suppressing mTOR/P70S6K signaling. Am J Transl Res 9: 1307-1316, 2017.

RAINES EW: PDGF and cardiovascular disease. Cytokine Growth Factor Rev 15: 237-254, 2004.

SCHULTZ-CHERRY S, MURPHY-ULLRICH JE: Thrombospondin causes activation of latent transforming growth factor-beta secreted by endothelial cells by a novel mechanism. J Cell Biol 122: 923-932, 1993.

SUKONINA V, LOOKENE A, OLIVECRONA T, OLIVECRONA G: Angiopoietin-like protein 4 converts lipoprotein lipase to inactive monomers and modulates lipase activity in adipose tissue. Proc Natl Acad Sci U S A 103: 17450-17455, 2006.

TOOLE BP, WIGHT TN, TAMMI MI: Hyaluronan-cell interactions in cancer and vascular disease. J Biol Chem 277 : 4593-4596, 2002.

VLACHOS IS, PARASKEVOPOULOU MD, KARAGKOUNI D, GEORGAKILAS G, VERGOULIS T, KANELLOS I, ANASTASOPOULOS IL, MANIOU S, KARATHANOU K, KALFAKAKOU D, FEVGAS A, DALAMAGAS T, HATZIGEORGIOU AG: DIANA-TarBase v7.0: indexing more than half a million experimentally supported miRNA:mRNA interactions. Nucleic Acids Res 43: D153-159, 2015.

WANG L, ZHENG J, DU Y, HUANG Y, LI J, LIU B, LIU CJ, ZHU Y, GAO Y, XU Q, KONG W, WANG X: Cartilage oligomeric matrix protein maintains the contractile phenotype of vascular smooth muscle cells by interacting with alpha(7)beta(1) integrin. Circ Res 106: 514-525, 2010.

WENDAN Y, CHANGZHU J, XUHONG S, HONGJING C, HONG S, DONGXIA Y, FANG X: BMSCs Interactions with Adventitial Fibroblasts Display Smooth Muscle Cell Lineage Potential in Differentiation and Migration That Contributes to Neointimal Formation. Stem Cells Int 2016: 3196071, 2016.

XU L, GUO ZN, YANG Y, XU J, BURCHELL SR, TANG J, ZHANG J, XU J, ZHANG JH: Angiopoietin-like 4: A double-edged sword in atherosclerosis and ischemic stroke? Exp Neurol 272: 61-66, 2015. 